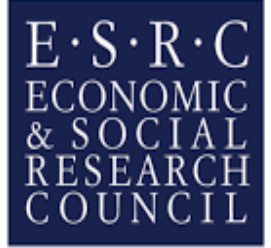

Research jointly supported by the ESRC and DFID

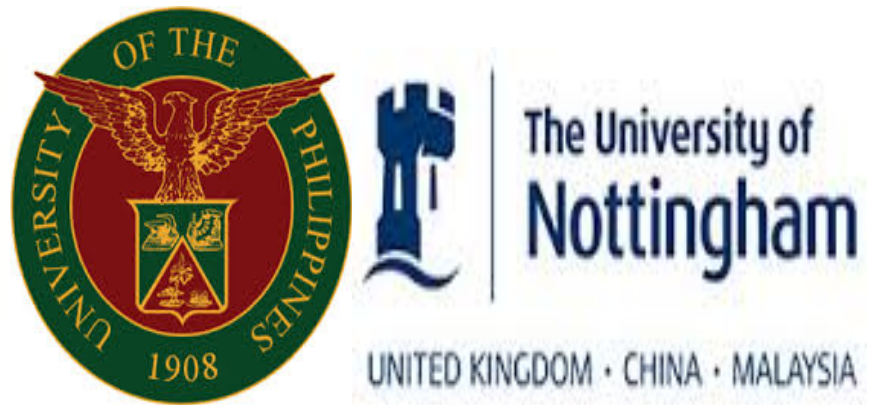

\title{
Gathering 'good' qualitative data in local communities post Typhoon Yolanda: power, conversation and negotiated memory (Working Paper IV)
}

\author{
By: Eadie, Pauline (University of Nottingham, UK); Galang, Clarence (University \\ of the Philippines Visayas Tacloban College) and Tumandao, Donabel (University \\ of the Philippines Visayas Tacloban College) ${ }^{1}$
}

Published March 2017

\section{Introduction}

This working paper is the fourth in a series run by the ESRC/DFID funded project 'Poverty Alleviation in the Wake of Typhoon Yolanda'2. This project monitors the effectiveness of the Typhoon Yolanda relief efforts in the Philippines in relation to building sustainable routes out of poverty. The project focuses on urban population risk, vulnerability to disasters and resilience in the aftermath of shocks such as Typhoon Yolanda. The key themes of the project are vulnerability, risk and resilience in relation to disasters and pathways in and out of poverty. Our work investigates post-disaster reconstruction efforts, specifically within densely populated coastal urban areas. These communities are amongst the most at risk and yet least able to resurrect themselves after disasters. Impoverished communities are often constructed in hazardous locations that are vulnerable to disasters. The poor are exposed to a

\footnotetext{
${ }^{1}$ Authors can be contacted as follows: Pauline Eadie, Pauline.Eadie@nottingham.ac.uk; Clarence Galang clarencegalang@ymail.com; Donabel Tumandao, beltumandao@gmail.com ${ }^{2}$ (Ref ES/M008932/1).
} 
greater degree of environmental exposure than the rich and "poor people are experiencing more disasters than non-poor people, ${ }^{3}$. A lack of land and resources, in states with varying degrees of wealth, dictates that the poor are most often located wherever they can find security of tenure, no matter how tenuous this might be, and where they can access material and social resources. Those living in coastal zones or other flood prone areas are most at risk from any climate-change induced severity such as storms or other extreme weather events.

Super-typhoon Yolanda ${ }^{4}$ (international name Haiyan) hit the Visayas region of the Philippines on 8 November 2013. Yolanda was one of the strongest typhoons ever to make landfall. Wind speeds reached in excess of $300 \mathrm{~km} / \mathrm{h}$ and the associated storm surge reached over five meters in places ${ }^{5}$. Official figures show that 6,293 individuals were reported dead, 1,061 went missing and 28,689 were injured. The Visayas region of the Philippines was totally ravaged by the storm and the damage to infrastructure is estimated at 17 billion PHP (US\$342,990,980) ${ }^{6}$. The typhoon affected 591 municipalities and the total damage is estimated at US\$904,680,000 ${ }^{7} .93$ percent of recorded deaths came from the Eastern Visayas (Region III) ${ }^{8}$. The total number of people affected by this disaster in terms of housing and infrastructure, livelihood, environmental and food security was approximately 16 million.

More than three years after Typhoon Yolanda rehabilitation efforts are still ongoing. An estimated 518,878 houses suffered total damage, 493,912 suffered partial damage

\footnotetext{
${ }^{3}$ Kim, Namsuk (2012) 'How much more exposed are the poor to natural disasters? Global and regional measurement', Disasters, Vol. 36, No. 2, pps. 195-211, p. 203.

${ }^{4}$ Eadie, Pauline (2013) 'Typhoon in Philippines Reveals Underlying Political Failings', Ballots and Bullets, 12 November. Available at: http://nottspolitics.org/2013/11/12/typhoon-in-philippines-revealsunderlyingpolitical-failings/. Accessed 5 June 2016

${ }^{5}$ For storm surge levels see: Lagmay, Alfredo M. F. (2014) 'Devastating Storm Surges of Typhoon Yolanda', Nationwide Operational Assessment of Hazards (NOAH)', Quezon City. Available at: http://blog.noah.dost.gov.ph/2014/06/02/devastating-storm-surges-of-typhoon-yolanda/. Accessed 12 January 2017.

${ }^{6}$ National Economic and Development Authority, Republic of the Philippines (2015) 'In Numbers: 2 Years After Yolanda', Pasig City. Available at: http://yolanda.neda.gov.ph/innumbers-2-years-after-typhoon-yolanda/. Accessed 10 January 2017.

${ }^{7}$ National Disaster Risk Reduction and Management Council, Republic of the Philippines, SitRep No. 108 Effects of Typhoon Yolanda (Haiyan), 3 April 2014. Available at: http://www.ndrrmc.gov.ph/attachments/article/1329/Effects_of_Typhoon_YOLANDA_(HAIYAN)_Si tRep_No_108 03APR2014.pdf. Accessed 5 June 2016.

${ }^{8}$ National Risk Reduction and Management Council, Republic of the Philippines (n.d.) 'Final Report re Effects of Typhoon Yolanda (Haiyan)', Quezon City. Available at: http://ndrrmc.gov.ph/attachments/article/1329/FINAL_REPORT_re_Effects_of_Typhoon_YOLA NDA_(HAIYAN)_06-09NOV2013.pdf. Accessed 10 January 2017.
} 
and nearly six million people lost their livelihood ${ }^{9}$. The practical objective of our project is to assess twenty typhoon-affected urban barangays ${ }^{10}$ across three Local Government Units (LGUs) in Region III in order to determine how and why poverty relief strategies work better or worse in different administrative units under similar post-disaster conditions over time. 17 of the barangays that were selected for this project are on the coast and therefore most at risk from typhoons. The remaining three barangays were relatively less affected as they are inland and/or on higher ground. These barangays serve as least affected controls however no barangays in the region were unaffected. All suffered a significant degree of damage, even if they were not affected by coastal flooding.

Without 'community participation, disaster relief often inadvertently rebuilds [...] structures of vulnerability, ${ }^{11}$ consequently this paper is based on the premise that local communities should be tapped for information that will support resilient and sustainable disaster relief strategies. 'Top down' donor driven strategies may fail to account for local socio-economic and environmental realities. This may lead to erroneous assumptions about local beliefs and values and how power and allegiance operate in local communities. These issues are of key importance as they dictate how people behave and why they cooperate or come into conflict. Local configurations of power can control or distort information gathering and in turn the distribution of goods and services.

Rehabilitation strategies that are informed by the survivors and self-assessment of their needs are desirable as solutions can then be devised that are context specific and hopefully more likely to be resilient in the longer term. However family and community based self-rated deprivation presents a number of challenges that are amplified in a post-disaster environment. This paper argues that whilst 'bottom up' driven disaster relief strategies have their merits; they also present a number of

\footnotetext{
${ }^{9}$ National Economic and Development Authority (2015), op.cit.

${ }^{10}$ The barangays are: Tacloban: Barangays 54, 54-A, 66-A, 67, 87, 88, 89, and Abucay (least affected); Palo: Cavite, Cogon, Libertad (least affected), Pawing, Salvacion, and San Joaquin; and Tanauan: Bislig, Calogcog, Salvador (least affected), San Roque, Sta. Cruz, and Sto. Niño.

${ }^{11}$ Bhatt, Mihir R. and Reynolds, Tommy (2012) 'Community- Based Disaster Risk Reduction: Realizing the Primacy of Community', in Emdad Haque, C. and Etkin, D. Disaster, Risk and Vulnerability: Mitigation through Mobilizing Communities and Partnerships, McGill-Queen's University Press: Montreal and Kingston, pps. 71-90, p. 74.
} 
challenges. These challenges include conflict over resources, the likelihood that those with political power at the local level are likely to promote the preservation of the status quo and tension between immediate needs/survival and the long-term sustainability of rehabilitation programs. We argue that aid agencies need to engage with local communities to gather 'good' data for forward planning. However, as beneficiaries are likely to have the 'expectation of reward or punishment', data gathering is a somewhat challenging process.

The aims of this paper are to examine the pros and cons of household interviews and examine the factors that impact upon the self-assessment of need. Disaster relief strategies that are based on flawed data are less likely to be cost effective and inequitable in terms of the allocation of goods or sustainable. Good data is important for disaster relief strategies including the effective development of local capacity building and preparedness for future disasters. Consequently it is important to be aware of the drawbacks of self-assessment, why skewed reporting might occur and what can be done to avoid, minimize and identify anomalies in the self-assessment of needs. This paper elaborates on a series of barangay (village) level interviews in 2015 and 2016 conducted by the investigators of this project ${ }^{12}$ and five local researchers ${ }^{13}$.

The first section of this paper offers a brief assessment of context specific and bottom up driven relief strategies and examines the pitfalls of self-rated poverty. We examine the tensions between top-down and bottom-up disaster relief strategies and argue that both approaches can suffer from politicking, subjective assessment of needs and multiple pressures on the direction and organization of any given policy. The second section of this paper discusses the rational for conducting household interviews. We also elaborate on the logistics of conducting the interviews and the ethical issues that we considered in relation to this process. In the following section we outline barangay politics and the role of barangay captains in order to highlight how local political power can potentially distort the data gathering processes. In the final section we

\footnotetext{
12 Thanks are due to the co-investigators of this project, Prof. Maria Ela Atienza and Prof May Tan-Mullins, for review comments on this paper. The primary investigator of this project is Dr. Pauline Eadie, co-author of this paper.

13 We would like to acknowledge the contribution of Galang, Clarence; Gerona, Christer K. 0; Tumanadao, Donabel; Rojas, Theresia K.; Villones, Marvie to this research. Galang and Tumanadao are co-authors of this paper.
} 
examine the issues and tensions that we experienced when conducting interviews with survivors. These tensions include contradictions in responses (even within the same interview); the presence of 'uninvited' friends and neighbours in interviews and the importance of anonymity. We offer a number of suggestions to ease control of the semi-structured interview process including the merits of interview by conversation and establishing a clear academic identity for the researcher. We also address anticipation of 'reward or punishment', the effect that this can have on the selfassessment of needs and why such anticipation makes it problematic for outside agencies to build an adequate picture of need. In conclusion we argue that researchers should devise systematic cross checking strategies to counter exaggerated, politically motivated or contradictory self-assessment. Self-assessment alone can be critiqued for lacking scientific rigour. However the contradictions and distortions inherent within self-assessment can also illuminate the local social context and that also has value in terms of devising effective, context specific, bottom-up post disaster strategies. In conclusion we argue that household interviews based on self-assessment can be very valuable however they need to be understood within the socio-cultural and material environment in which they are held in order to be fully understood.

\section{Disaster, Context and Self-rated Poverty}

In order to create sustainable disaster relief solutions it is desirable for survivors to become active participants in disaster relief services as opposed to passive recipients of those services. More broadly sustainable development ${ }^{14}$ and disaster relief practitioners ${ }^{15}$ now recognize the merits of bottom up approaches. Disaster relief and rehabilitation strategies should be context specific. 'One size fits all' solutions driven from the top have been critiqued as unsustainable over the longer term, especially when the support mechanisms and funding from outside donor programs ends. In order to be durable over the longer term 'context' has to be understood politically,

\footnotetext{
${ }^{14}$ See i.e. Fraser, Evan D. G. et. al. (2005) 'Bottom up and Top Down: Analysis of participatory processes for sustainability indicator identification as a pathway to community empowerment and sustainable environmental management' Journal of Environmental Management, Vol. 78, pps. 114-127; Power el. Al. (2002) 'Operationalising bottom up learning in international NGOs: barriers and alternatives' Development in Practice, Vol. 12, Nos. 3 and 4, pps. 272-284 .

15 See i.e. Osti, Rabindra (2004) 'Forms of participation and agencies' role for the implementation of water-induced disaster management: protecting and enhancing the poor', Disaster Prevention and Management: an international journal, Vol. 13, No. 1. pps 6-12.
} 
socially and materially. However societies inevitably change after a disaster. As well as material loss disasters can affect 'social norms, attitudes, trust, and reciprocity of people within communities ${ }^{\prime 16}$. Consequently, the post-disaster 'context' is a moving target and resilience is not just about recreating the society that was destroyed or staying the same. Thus it is crucial that governmental and non-governmental agencies take account of the voices of the people themselves in order to understand context and the material and social criteria necessary for positive change and sustainable rehabilitation.

Top-down solutions may fail for a number of reasons including time constrained project funding, competition from elsewhere over resources, political maneuvering and the need for governmental and non-governmental agencies to be seen to be doing 'something'. These issues may result in a preference for media friendly activities. Outside agencies may not be familiar with the socio-economic, ecological or political context of a locality and under emergency conditions it is easier to resort to standard operating procedures in order to save lives and meet immediate basic needs. Meanwhile bottom-up driven solutions may fail because they are inward looking, focused on the short-term, overly subjective and suffer from a lack of resources and coordination. There may also be a mindset amongst survivors that if aid is offered it should be taken, whether it is needed or not, when the opportunity presents itself as assistance may cease in the future. However, as we will detail later in this paper, political maneuvering takes place at the bottom as well as at the top.

Relief agencies need data after major disasters so that sustainable solutions, that best serve the needs of survivors, can be devised. Good data is necessary so that 'priorities can be set and enforced [as] gaps and duplication may have fatal consequences that are less excusable given the extraordinary generosity of the assistance from countries and individuals ${ }^{17}$. Benchmark data such as census or barangay records may be readily available however such data can be quickly outdated or lost in disasters. A

\footnotetext{
16 Fleming, David A. (2014) 'Trust and Reciprocity in the Aftermath of Natural Disasters', Vol. 50, No. 11, pps. 1482-1493, p. 1482.

17 De Ville de Goyet, Claude, (2008) 'Information Gaps in Relief, Recovery, and Reconstruction in the Aftermath if Natural Disasters' in Amin, Samir and Goldstein, Markus P. (eds.) Data Against Natural Disasters: Establishing Effective Systems for Relief, Recovery and Reconstruction, The World Bank: Washington, pps. 23-58, p. 34.
} 
number of the barangay captains that were interviewed for this project complained that relief goods were distributed on the basis of the 2010 Philippine Census on Population and Housing. However, by 2013 the population had grown significantly meaning that the goods received were not enough for the barangay.

Aid allocation may also suffer from arbitrary cut off points that designate survivors beyond that point as self-sufficient or in need of only limited assistance. The end result of such a cut off point is a false dichotomy between those survivors above and below the 'poverty line'. Survivors may also fail to secure relief goods and services, as they are not recognized as qualified beneficiaries. In the aftermath of Yolanda government and aid agencies were heavily reliant on barangay captains to identify beneficiaries. This led to a number of disgruntled residents complaining that inclusion on the list was 'colour-coded', in other words dependent on political allegiance to the barangay captain. Further up the political chain of command local residents expressed the view that the allocation of aid to the barangays was also dependent on whether the barangay captain was politically allied with the mayor or not. Over the longer term skewed distribution of resources may lead to debt and impoverishment, as those deemed to be self-sufficient or ineligible have to find alternatives ways to self-fund their rehabilitation after a disaster.

For disaster relief agencies attempting to generate robust data that can be used as a baseline for their programs it is problematic in that survey respondents may anticipate 'reward or punishment for any reply' ${ }^{18}$. Self-rated poverty in the aftermath of a disaster, under conditions when, sometimes significant aid flows are present, is problematic. Multiple agencies with overlapping objectives might approach survivors who may reach the stage of 'survey fatigue'. If or when this stage is reached survivors are likely to fail to engage fully with the survey process, exaggerate their needs or accept types of aid that they don't have a use for. Such responses will affect the efficiency of donor agencies as they may plan their strategies based on false or partial information. This problem is compounded as 'the critical difference between the bottom-up and the top-down approaches to poverty measurement lies in whatever differences there may be between the (subjective) norms of the people at the bottom

\footnotetext{
18 Ibid, p. 42.
} 
and the (equally-subjective) norms of some people at the top ${ }^{, 19}$ (original emphasis). In other words poverty alleviation and rehabilitation strategies suffer from a dual subjectivity from both the bottom and the top. In light of the critique of self-rated poverty outlined above the following section outlines the rationale and organization of our household interviews.

\section{Rationale and Conduct of Family Interviews}

Our questions were aimed at establishing the effect of Yolanda and the subsequent relief and rehabilitation efforts on household and community capacity. The objective of the Philippine government's Reconstruction Assistance on Yolanda (RAY): Build Back Better strategic plan was to 'guide the recovery and reconstruction of the economy, lives and livelihoods in the affected areas [and] to restore the economic and social conditions of those areas at the very least to their pre-typhoon levels and to a higher level of disaster resilience ${ }^{20}$. Information on the aims and objectives of policy makers and relief agencies was relatively easy to find. However it was less easy to get a systematic snapshot of the lived experience of survivors.

In order to fill that gap we chose to conduct $40^{21}$ in-depth interviews with families across the 20 barangays that are the focus of this research. We identified two households in each barangay. In order to identify suitable families we approached the barangay captains who directed us to one most affected and one least affected family that were willing to be interviewed. By selecting 20 most affected and 20 least affected families we aimed to establish the factors that helped or hindered rehabilitation given their similar but perhaps different experiences. We asked every family the same questions. By interviewing 40 families in a semi-structured and systematic fashion we aimed to go beyond mere anecdotal evidence. However our questions were framed to allow for probing questions to also be asked. Respondents were specifically asked to give examples of any generalized claims that they made and to be a specific as possible about the types and sources of aid that they received.

\footnotetext{
${ }^{19}$ Mangahas, Mahar (1995) 'Self-rated Poverty in the Philippines, 1991-1992, International Journal of Public Opinion Research, Vol. 7, No. 1, pps. 40-55.

${ }^{20}$ (n. a.) (2013) Reconstruction Assistance on Yolanda: Build Back Better, 16 December, National Economic and Development Authority (NEDA): Pasig City, p. p.1.

2140 follow interviews with, as far as possible, the same families will be conducted in July 2017.
} 
We also interviewed each barangay captain annually for the duration of our project. Similar probing questions were used with the barangay captains. In both cases we took care to avoid giving suggestions to answers, unless it was to clarify the question. We also avoided 'leading questions' as we wanted to capture the point of view and lived experience of the respondent. We also took care to allow for silence as respondents thought about their replies, only breaking that silence to ensure that the respondent had understood the question. From the responses we gathered we were able to build a relatively comprehensive picture of capacity building strategies at the barangay level and the factors that that served to facilitate or undermine these strategies.

We were particularly interested in testing whether the lived experience of survivors corroborated the claims that governmental and non-governmental agencies were making about the recovery efforts. If agencies were claiming success when in fact this was partial or non-existent it is important to identify this so that future practice can be improved. It is also important to identify issues that are significant to survivors, but might be missed by outside agencies that are guided by their own agendas so that these issues can be factored into future policy.

We were also interested in assessing the extent to which survivors thought that communities pulled together in the aftermath of Yolanda and whether outside agencies facilitated community cohesion and in turn community resilience. This is because Building Back Better must promote fairness and equity and 'recognize that families and communities drive their own recovery ${ }^{22}$. Building Back Better is not just about material construction; it is about rebuilding communities, and who better to report on that than the people themselves. The household interview evidence has been cross-referenced with our survey results ${ }^{23}$, focus group discussions and governmental and non-governmental interviews. The picture that we have been able to build with our primary evidence has also been cross-referenced with primary and secondary

22 Clinton, William J. (2006) Key Propositions for Building Back Better: Lessons Learned From Tsunami Recovery, Office of the UN Secretary General's Special Envoy for Tsunami Recovery: New York, p. 1. Available at: http://www.preventionweb.net/files/2054_VL108301.pdf. Accessed 25 January 2017.

23800 surveys were conducted each year for three years. 2400 in total across the selected barangays. 
evidence from other sources including agencies working in the same barangays in which we conducted interviews.

The household interviews were conducted by young Filipino academics from University of the Philippines Visayas Tacloban College (UPVTC). This was a deliberate strategy aimed at minimizing calculations of reward or punishment ${ }^{24}$ that might have distorted responses. The interviewers were not foreign and they were clearly not from an aid agency or government office. They were also familiar with the local area and some of them were themselves, Yolanda survivors. All interviews were anonymous and the interviews were conducted in the local Waray dialect. The local language skills of the interviewers allowed the respondents to converse in the language they were most comfortable using. The questions asked allowed for openended responses, this differed from the survey questions that worked on the basis of tick boxes that could be used to generate statistical data. Each family that we interviewed was given a food pack as a token of our appreciation for their assistance.

\section{Political Considerations}

Barangay councils are composed of a barangay captain and barangay kagawads or councilors. These elected officials act as village elders. They work with numerous outside agencies and deal with local disputes. As stipulated in Section 12 of RA 10121, the barangay captain heads the Barangay Disaster Risk Reduction and Management Committee which is at the forefront of disaster risk reduction and recovery at the barangay level. ${ }^{25}$ Barangay captains played a crucial role in disaster preparation and recovery before and after Typhoon Yolanda.

Barangay officials are normally elected for three-year terms. In 2013 barangay elections were held on 28 October, with the term of office starting on 30 November. This meant that officials were elected two weeks before Yolanda hit on 8 November and took office three weeks after. The 2016 election was suspended due to President Duterte's fear that drug money would be used to 'fund the campaigns of those

\footnotetext{
${ }^{24}$ We recruited local students to conduct our surveys for the same reason.

${ }^{25}$ Republic of the Philippines (2010) Disaster Risk Reduction and Management Act of 2010. Available at: http://www.gov.ph/1991/10/10/republic-act-no-7160/. Accessed 18 December 2016.
} 
running for barangay posts, ${ }^{26}$. Duterte also wanted to press on with infrastructure projects and avoid the 45-day ban on public works and disbursement and expenditure of public funds before and after every election. This ban is in place so that unscrupulous officials can't curry favour with the electorate by ensuring that much needed infrastructure projects coincide with the campaign period. The 2016 ban meant that the barangay officials in office during our project, notwithstanding some other reason for leaving their posts, were in their posts shortly after Yolanda hit the region in 2013. Frequently they were already serving as barangay captains or barangay council members during Yolanda so they were involved with the management of the community during the actual disaster.

In the first year of our project we visited the captain of every barangay in the area under research. At that point we introduced ourselves, and the project, and conducted an initial interview. We also presented the captains with a certificate giving details of the universities and funders sponsoring the project and thanking them for their participation. These initial introductions were essential as the captains are in effect the gatekeepers to the community. It would have been difficult for subsequent interviews and surveys to be conducted in the barangay without first going through these formalities. In due course it was the barangay captains that we turned to in order to identify suitable families for our household interviews.

However there were some setbacks to this approach. In the aftermath of Yolanda governmental and non-governmental aid agencies were heavily reliant on barangay captains for accurate data on the number of and needs of survivors. Barangay captains were tasked with listing qualified beneficiaries in relation to e.g. residence, dependents and age. Barangay captains wielded a significant degree of power over the allocation of resources. Many interviewees appeared reluctant to complain or openly criticize their barangay captains in order to avoid animosity that could potentially lead to them being struck off the beneficiary list ${ }^{27}$.

\footnotetext{
${ }^{26}$ ABS-CBN News (2016) 'Why DILG wants barangay, SK polls suspended', 30 August. Available at: $\quad$ http://news.abs-cbn.com/news/08/30/16/why-dilg-wants-barangay-sk-polls-suspended. Accessed 6 February 2016.

${ }^{27}$ See also Sumagaysay. Marietta, et al. (2016) 'Promoting Democratic Accountability, Providing Permanent Housing to Survivors of Typhoon Haiyan in Palo', Leyte in Building Back Better: A Democratic Accountability Assessment of Service Delivery After Typhoon Haiyan, University of the Philippines Center for Integrative and Development Studies. pps. 29-45.
} 
The control over beneficiary lists is potentially an opportunity for patronage politics. Patronage can be defined as cash, goods or economic opportunities that are distributed in exchange for political support. ${ }^{28}$ Patronage is particularly evident before and after elections. Before elections patronage secures political support. After elections it rewards supporters and maintains loyalty. The relationship through which patronage is distributed is called clientelism ${ }^{29}$, a known phenomenon in the Philippines. Therefore it is important to consider interviewee responses in the context of potential reward or punishment for political alignment or dissent. For this reason anonymity played a crucial role in the interview process.

Some barangay captains recommended respondents who appeared to be political allies, even offering their barangay officials as respondents. Interviewees were quite open about their relationship to the barangay captain, which was based on either consanguinity or political affiliation. For example, in the selected barangays in Tanauan, one respondent was a brother of the barangay captain, one was the husband of the barangay secretary and one was the sister of a barangay health worker ${ }^{30}$. The relationship also became evident when these respondents were asked questions related to the barangay officials. Respondents would be profuse with their praise or dismiss the criticism of opponents. For example, some interviewees explained that the residents that complained about the 'unfair' allocation of resources were opponents of the barangay captain. These respondents dismissed complaints as 'politically motivated' allegedly aimed at tarnishing the image of the barangay captain.

Many of the interviewees showed willingness to be interviewed and answered the questions freely, even sharing personal experiences not directly linked to the set interview questions. However, there were instances when respondents appeared

\footnotetext{
${ }^{28}$ See e.g. Kerkvliet, Benedict J. T. (1995) 'Toward a More Comprehensive Analysis of Philippine Politics: Beyond the Patron-Client Factional Framework, Journal of Southeast Asian Studies, Vol. 26, No. 2, pps. 401-419; Quimpo, Nathan G. (2005) 'Oligarchic Patrimonialism, Bossism, Electoral Clientelism, and Contested Democracy in the Philippines', Comparative Politics, Vol. 37, No. 2, pps. 229-250.

${ }^{29}$ See Hicken. Allen (2011) 'Clientelism', Annual Review of Political Science, Vol. 14, pps. 289-310.

${ }^{30}$ However the line between community and family is a blurred line in many barangays as commonly the population is composed of many extended families. No matter who we chose to interview or survey a blood tie was likely. This situation meant that it was hard to draw a definitive line between community solidarity and family ties when assessing the social bonds in the aftermath of Yolanda.
} 
compelled to answer only because they were the ones assigned by the barangay captains. There were also instances when the respondents were hesitant in answering questions about the barangay officials for fear of offending them The respondents gave consent to record the interview, however when some questions about their barangay officials were asked, they became wary of answering freely as they feared that the recording might reach their barangay officials and might be used against them. When one respondent ${ }^{31}$ was asked about the allocation of resources, she became reluctant ${ }^{32}$ to respond to the question and argued: Bangin nim liwat ako igsumat kan kapitan, ebidensya mo gud ini (You might report me to our barangay captain, this [recording] could be your evidence).

An understanding of local power configurations is essential for aid agencies hoping to develop 'bottom up' driven rehabilitation strategies. The evidence that we gathered sometimes indicated an equitable and dynamic barangay captain. In other cases residents were anxious about the maldistribution of aid and expressed concerns that resources were channeled to those related to, or politically affiliated with, the barangay captain. 'Expectations of reward or punishment' relate to not only the goods and services that aid agencies deliver but also how barangay captains control the flow of these resources. This issue is of primary importance to those seeking to gather 'good' data at the local level. The practical logistics of family interviews and the data gathering process are elaborated on in the next section.

\section{Rapport Building and Interview By Conversation}

Finding household respondents may be relatively easy. The real challenge for interviewers is to encourage respondents to reply openly and honestly with an adequate focus on the question. Anonymity and ensuring that the project and the researcher have no local political agenda is essential to ensure trust. Our political neutrality was aided by our explanations of the project to the barangay captains and our use of official academic project identification cards for researchers. Respondents

\footnotetext{
31 Barangay name removed to ensure confidentiality.

32 This reluctance to be critical was also seen in the responses of some of the barangay captains who were sometimes wary of commenting on their respective mayors on tape. Many barangay captains talked fondly of their mayors, however they were only candid about vote buying in the 2016 mayoral (and regional and national) elections once the tape had been switched off.
} 
were also told that if they were uncomfortable with a question or were not confident with an answer then they could just indicate that they wanted to move on to the next question.

We found that, in practice, the semi-structured interviews became interviews by conversation, as respondents were also interested in the interviewer. Interviews are in effect ordered conversations but apart from the semi-structured element of the engagement 'the interview responds to precisely the same kinds of opportunities and constraints as "ordinary" conversation, ${ }^{, 33}$ in that communication is a two way process. The conversation element of the interviews was evident in interviews with the householders and the barangay captains. Often the interviewer was asked about their families, religion, careers, origins and overall purpose of the project. The conversational element of the interview is useful as it can help the respondent feel at ease, and therefore more talkative, and on a par with the interviewer.

Camaraderie was built with some of the barangay captains by the time of the second year of interviews and it was relatively common to stay and talk informally after the tape was switched off. We took merienda (snacks) for the barangay captains and often we were offered food by way of hospitality in return. These social processes helped to build trust amongst the interviewee and the interviewer. It was also important that the project was properly explained to everyone that asked otherwise there is the danger that people will resent that fact that their experience, knowledge and even images are expropriated without any discernible benefit to themselves.

The very presence of strangers in the barangays draws attention. Filipinos are social, curious and hospitable. Residents were happy to give directions, even accompanying researchers to the houses of interviewees. We were asked about our intentions in the barangay, the agency that we represented and why we were only interviewing two households in the barangay. Even in the middle of interviews, inevitably some passersby approached and asked questions about the interview. It was common for interviewees to welcome friends and neighbors into the house whilst the interview

\footnotetext{
${ }^{33}$ Blommaert, Jan and Dong, Jie, 2010, Ethnographic Fieldwork: A Beginners Guide, Multilingual Matters: Bristol, p. 44.
} 
was taking place. This meant that the interview turned into a group process. In the Philippines this is an entirely normal process and should be expected.

During such unintentionally 'communal' interviews additional attendees sometimes interrupted if the householder was slow to answer a question or could not remember. This meant that the eventual response of the householder was conditioned by the response already given. It also meant that the opportunity for 'silent probes' was lost. Allowing for silence in interviews is an important way of prompting a response. Interviewers should not rush to fill silence or finish sentences, however the vocal extra attendees disrupted the silence. Interviewees also got cut off during the interview if their friends found their responses to be incorrect or in need of elaboration. Some interviewees were also happy to let their friends narrate some of their shared experiences during the typhoon especially if they stayed in the same evacuation area. It is impossible to know how the same interview would have played out without the presence of the friends. The communal aspect of the interview allowed the interviewer to further understand local dynamics within the community but the group situation undermined the anonymity of the interview and potentially made interviewees less critical of barangay captains and other residents.

Ideally interviewers should conduct interviews in a distraction free location. However this was not always possible in the crowded barangays, houses are often small, very close together and near busy walkways. Houses might lack windows, only having holes that can be shuttered, so privacy is compromised. Multiple occupants and visitors might be present during the interview, including small children who require the attention of their parents. However the household is often the most convenient place for the interviewee to be available and the place in which he/she feels most at ease. It is unwise for the interviewer to eject friends and neighbours if the householder has invited them into the house as this could be seen as rude.

\section{Tokens}

Tokens can play a significant role in easing the process of the interviews. Each household respondent was given a food pack of noodles and some tinned goods in recognition of their contribution to the project and as an incentive to take part. It is 
usual, and was the experience post Yolanda, for donors to conduct surveys and interviews before giving aid to typhoon victims. Therefore 'a culture of expectation, 34 was already established which meant that people automatically expected aid or reward from anyone conducting interviews in the barangays. This can result in an eagerness to be interviewed and an emphasis on indigence linked to the expectation of reward or punishment. It is therefore important that academic researchers conducting surveys and interviews emphasize that the work is academic and not related to a funding agency.

In practical terms our researchers did not visibly carry tokens in order to avoid attracting respondents that were not needed. We also made a deliberate decision not to give out cash incentives. This was because we did not want our interviewers to be known to be carrying relatively large sums of money around and we wanted to avoid funding expenditure on 'negative' commodities such as alcohol or cigarettes. Nevertheless some residents did volunteer to become respondents when they realized that the interviewers were giving out tokens to households that were interviewed. In some cases the unintentionally communal interviews outlined above created a problem as the uninvited interviewees also expected a token. When planning fieldwork and research projects it is advisable to factor in the cost of tokens, the difficulty of transporting larger items such as canned goods (perishable goods should be avoided) and the need to strike a balance between accounting for extra tokens that might be needed whilst keeping within the project budget. In practice we found that it was sometimes hard to control the number of attendees at interviews and focus groups.

\section{Inconsistency in responses}

During the conduct of family interviews, the interviewers noticed several contradictions and inconsistencies in the answers given by the respondents. These were not only apparent among those living in the same areas, but also even within the same interview with the same respondent. For instance:

\footnotetext{
${ }^{34}$ Head, Emma, 2009, 'The ethics and implications of paying participants in qualitative research', International Journal of Social Research Methodology, Vol. 12, No. 4, pps 335-344, p. 343.
} 
- A broad question of whether the community has improved met with a response that 'the community is still the same'. However, in the same interview, a related question regarding the status of community participation and cohesion, met with the response that 'the community has improved and people were helpful to one another'. The second answer gave credit to Tzu Chi's cash for work program ${ }^{35}$ as a driver of community building. Other interviewees corroborated this view ${ }^{36}$.

- An interviewee was asked whether there is an improvement in their family's situation and answered that there was 'none at all'. But when asked to compare their situation before and after Yolanda, the respondent answered that 'life is better now'. The latter answer was linked to an additional source of income from a new 'sari-sari' store.

- A respondent stated that barangay officials tampered with master lists that were used to assign aid to beneficiaries. However when asked what would he have done differently, if he were in the position of personnel or agencies giving out aid, he answered 'nothing'. Even though he was aware of anomalies in the lists.

Inconsistency in responses was also noted in other interviews and focus group discussions. There are several evidence-based reasons for these inconsistencies. Firstly many people in a post-disaster environment perceive that any stranger entering their community is there to distribute aid. This means that when interviewees are asked about their situation their initial response is likely to indicate that it is "not improved' or 'still the same' as they anticipate reward or punishment for their answer. However their negative response is then contradicted when they expand upon the actual detail of the situation. Secondly some respondents were reluctant in answering questions concerning the barangay officials especially about the barangay captains because they are afraid that these officials will be privy to the interviews. This meant that whilst problems with the lists were raised this was also dismissed as 'inevitable'.

\footnotetext{
35 n. a., 2013, 'One month after Yolanda: Cleaner Streets, hopeful lives', Taiwan Buddhist Tzu Chi Foundation. Available at: http://tzuchi.org.ph/special_report/one-month-after-yolanda-cleanerstreets-hopeful-lives-2/. Accessed 8 February 2017.

${ }^{36}$ The psychosocial benefits of cash for work have also been noted in other post disaster situations. See e.g. Doocy, Shannon et. al., 'Implementing Cash for Work Programmes in posttsunami Aceh: experiences and lessons learned' Disasters, Vol. 30, No.3., pps. 277- 296.
} 
Thirdly, friends and neighbours, who shared the same experience of disaster, might contradict each other over where disaster relief came from. This is because multiple agencies worked within the same areas and answers were based on individual personal experiences and these experiences were not identical.

We suggest that inconsistency in response might be managed in the following ways. Firstly probing questions can play a useful role in drawing out accurate information. Sometimes respondents get tired of answering questions and so when asked something general that needs extensive thinking, they tend to opt for a limited response or no answer at all. In order to limit this we specifically avoided asking questions that were likely to result in a simple 'yes or no' response. However if a limited response is offered probing questions can help to jog memory and focus responses on the specifics of an issue. The step-by-step nature of some probing questions can help researchers to gather more information. Probing questions can be factored into the prepared list of questions but they can also be generated spontaneously by the unstructured flow of interview by conversation. Secondly inconsistency in responses should not be dismissed as lies or confusion. People inevitably construct, reconstruct and embellish their own memories and narratives of events and the specific of these narratives may differ over time and between people who have undergone the same experience. The inconsistent responses should be recorded and crosschecked against other primary and secondary information in order to generate a fuller picture of events. This process of cross-checking is equally important for aid agencies. We found that, in practice, some aid agencies crosschecked information from beneficiaries with barangays captains and municipal and city hall records, but some did not.

\section{Conclusion}

'Natural' disasters on the scale of Typhon Yolanda can have a material and social impact akin to that of a major war. Governmental and non-governmental aid agencies face significant challenges in meeting short-term basic needs and devising rehabilitation solutions that will help communities regenerate and become resilient over the longer term. Sometimes 'natural' disasters are part and parcel of complex emergencies characterized by political instability, ethnic conflict and other forms of 
violence. This was not the case after Typhoon Yolanda, nevertheless tensions between local and national government offices, social inequality and underlying poverty created a number of challenges. Governmental and non-governmental agencies have a duty to serve disaster struck communities, make the most of available resources, and satisfy donors and tax payers that their money is not being wasted. It is incumbent upon agencies to devise contextually relevant and sustainable solutions. It is therefore essential to involve beneficiaries and local stakeholders in the design and delivery of recovery and rehabilitation initiatives. It is important to take account of local sociocultural beliefs and practices during the rebuilding process. It is also essential to take account of power configurations, as constructions of both custom and legislation, within families, communities and local government.

Rebuilding is not just about the provision of material goods. It is also about social need, adaptation and the reconstruction of resilient communities. This means that recovery programs must incorporate the views and assessment of the survivors themselves. However self-rated need, especially in post-disaster situations, is liable to be distorted by the anticipation of reward or punishment. This poses a number of challenges for academics and practitioners aiming to gather robust data in post disaster environments. This leads us to the following conclusions.

Household interviews can result in a wealth of information. However power holders within local situations, in this case the barangay captains, can potentially censure or distort the data gathering process by guiding researchers towards trusted associates and even family members. For this reason it is essential to interview a sample of the population large enough to allow for the cross checking of responses. In our case our two family interviews per barangay (40 in total annually) were complemented with 40 surveys per barangay (800 in total annually), interviews with a range of governmental and non-governmental officials. These interviews were conducted on a repeat basis over three years. Primary data was crosschecked against other available primary and secondary data, including data from the city and municipal halls in the three LGUs under research. Household interviews are useful to get a deep understanding of peoples' experiences and situation. However the information gathered has to be dealt with as systematically as possible before validity can be claimed. It is not enough for researchers to visit communities and take reported problems at face value. 
It is helpful to research the specific experience of particular cases before conducting fieldwork. We researched the situation in the chosen barangays prior to field research in order to familiarize ourselves with the political context and specific experience of Yolanda within that barangay. Over 6000 people died during and shortly after Typhoon Yolanda so it was important that we approached our task with a certain degree of sensitivity. The coastal barangays that we chose were 'most similar' but their experience was not identical. The chosen barangays had already featured in the national and international news. It was important to be aware of these stories as it helped contextualize the first hand accounts that we heard.

Potentially aid agencies that have personnel already working in communities before a disaster have an advantage as they are trusted and have an intimate knowledge of local practices and behaviour and the political set-up. This is not always possible but certainly we observed many instances of international NGOs hiring local workers who already had local experience in particular fields such as health and livelihood. International NGOs also set up partnerships with local community based organizations (CBOs). Whilst local hiring and partnerships are generally to be commended often projects were only temporary. In some cases this led to claims that initiatives were 'orphaned' by their international sponsors.

Researchers and aid agencies face limitations in terms of time, money and pressure to produce results. Ultimately aid agencies may give in to the temptation to give the type of aid that they want to or have available as opposed to listening to the locals and cross checking reported need with the local authorities. If the locals are telling a confused or inconsistent story, this temptation is likely to get stronger. The end result could be wasted resources and unsustainable strategies that contribute towards continuing vulnerability in disaster prone and/or impoverished communities.

A working knowledge of pre-disaster political alliances is important, as these alliances tend to shape or influence the distribution of relief goods and services and rehabilitation efforts. After Typhoon Yolanda aid agencies had to navigate power configurations within barangays in order to identify qualified beneficiaries. However 
this process was widely critiqued as being politically driven ${ }^{37}$. Donors should therefore enforce transparency in the listing of recipients and undertake counterchecks to improve veracity. Academic researchers must be mindful of the post-disaster political context. Debts of gratitude or resentment against the barangay captains can colour the self-assessment of survivor experiences and need. The political setting of the locale can distort the responses of interviewees who are guided by their relationship to their 'patrons'. Patrons might be local political families including barangay captains and their relatives.

Top-down and bottom-up driven disaster relief strategies can both be politicized and subjective. Bottom-up strategies may suffer from skewed self-assessments of need however they are valuable in that they can illuminate the social as well as material context of post disaster environments. The specific concerns of community members can be addressed because the information comes directly from them. However, as presented in this paper, self-assessment of needs in a post-disaster context can be problematic. The anticipation of reward or punishment can skew answers.

However rather than abandon self-assessment it is incumbent on researchers to adapt their practices to account for such distortions by tailoring the format and conduct of their interviews to best reveal reliable responses that inform 'good data'. Anonymity is essential to the interview process. If interview questions are not crafted in the local language it is essential to have them translated. It is also useful for interviewers to be fluent in the local language. Questions should be focused but also allow for further 'probe' queries that allow for in-depth answers. Interviewees should be flexible enough to accommodate an 'uninvited' audience to the proceedings whilst also keeping control of the situation. Interviewers should also be objective, whilst general sympathetic overtones can build affinity with interviewees, moral judgment on reported behaviour in the barangays does not help the research process. The resulting data should also be subject to a systematic process of crosschecking with other available resources. Trust should be build with interviewees and anonymity must be

\footnotetext{
37 This was also the case at the national and LGU level. Patronage and debts of gratitude or resentment extend to local mayors and regional and national political personalities. Barangays are not self-contained political units, they nest within a hierarchy of jurisdictions across which a network of political loyalties operate.
} 
guaranteed. It should also be clear to respondents that academic researchers have no control over the allocation of aid. 